\title{
( 4 Cardiopulmonary resuscitation with assisted extracorporeal life-support versus conventional cardiopulmonary resuscitation in adults with in-hospital cardiac arrest: an observational study and propensity analysis
}

\author{
Yih-Sharng Chen*, Jou-Wei Lin*, Hsi-Yu Yu, Wen-Je Ko, Jih-Shuin Jerng, Wei-Tien Chang, Wen-Jone Chen, Shu-Chien Huang, Nai-Hsin Chi, \\ Chih-Hsien Wang, Li-Chin Chen, Pi-Ru Tsai, Sheoi-Shen Wang, Juey-Jen Hwang, Fang-Yue Lin
}

Lancet 2008; 372: 554-61 Published Online July 7,2008 DOI:10.1016/S01406736(08)60958-7 See Comment page 512

*These authors contributed equally

Department of Surgery (Y-S Chen MD, H-YYu MD, W-J Ko MD, S-C Huang MD, N-H Chi MD, C-H Wang MD, P-RTsai RN, S-S Wang MD, F-Y Lin MD), Department of Medicine (J-S Jerng MD, W-J Chen MD, L-C Chen RN, J-J Hwang MD), and Department of Emergency (W-T Chang MD), National Taiwan University Hospital, Taipei, Taiwan; and Cardiovascular Center, National Taiwan University Hospital Yun-Lin Branch, Dou-Liou City, Yun-Lin, Taiwan (J-W Lin MD, J-J Hwang)

Correspondence to:

Fang-Yue Lin, Department of Surgery, National Taiwan University Hospital, Taipei 100, yschen1234@gmail.com Taiwan

Sudden cardiac arrest still has a low survival rate despite the introduction of cardiopulmonary resuscitation $(\mathrm{CPR}),{ }^{1}$ and this rate has remained unchanged since 1993..$^{2,3}$ Investigations have also shown that survival rate declines rapidly when the duration of CPR exceeds $10 \mathrm{~min}$, and even more rapidly if it exceeds $30 \mathrm{~min} .^{3-5}$

Extracorporeal life-support as a device for cardiac resuscitation was proposed in the early $1960 \mathrm{~s} .{ }^{6}$ Advances in technology have allowed such treatment to be deployed rapidly, and several descriptive series investigations have shown encouraging outcomes in patients with cardiac arrest. ${ }^{7-9}$ Despite promising results in paediatric patients, ${ }^{10-12}$ no comparative data have been assessed in adult groups undergoing CPR assisted with extracorporeal life-support.

Since protracted conventional CPR has been associated with high immediate mortality, 4,5 we did a prospective observational study, between 2004 and 2006, of adults with in-hospital cardiac arrest of cardiac origin who received CPR of more than $10 \mathrm{~min}$. We also aimed to assess whether the survival benefit of extracorporeal CPR over conventional CPR seen in previous studies ${ }^{7-9}$ might $^{-}$ have been due to selection bias.

\section{Methods}

\section{Setting}

National Taiwan University Hospital, in Taipei, is an extracorporeal life-support referral centre. ${ }^{13-15}$ The CPR team consisted of a senior medical resident, several junior residents, a respiratory therapist, a head nurse, and several registered nurses from the intensive care unit. Each member of the CPR team is certified for advanced cardiac life-support. According to American Heart Association guidelines, ${ }^{16}$ we established an internet-based Utstein style registry system to prospectively obtain all data for in-hospital cardiac arrest since 2003 (webpanel 1). A registered nurse was responsible for data collection. Each event was reviewed 
and discussed by the IHCA (in-hospital cardiac arrest) task force committee to discover the possible cause of cardiac arrest at the end of the hospital treatment (webpanel 2). The task force consisted of cardiovascular surgeons, anaesthetists, and critical care specialists under the direct supervision of the Centre of Quality Management, which has supervised 70-100 extracorporeal life-support procedures a year for the past 5 years. Patients surviving to discharge were followed-up for at least a year. In-hospital and out-of-hospital information was traced and placed online with authorised access.

\section{Patients}

We included adults with in-hospital cardiac arrest of cardiac origin (as established by two independent committees), aged between 18 and 75 years, who underwent CPR for longer than $10 \mathrm{~min}$ between Jan 1, 2004, and Dec 31, 2006 (webfigures 1 and 2). An in-hospital cardiac arrest was deemed to be of cardiac origin if there was evidence of raised cardiac enzymes before CPR, sudden collapse without obvious causes, sudden collapse with pre-existing cardiovascular disease, or other expressions approved by the task force committee. Only patients who underwent witnessed arrest of cardiac origin and CPR duration (defined as the interval from beginning CPR to return of spontaneous circulation or death) for more than 10 min were recruited in the study cohort. Those who received extracorporeal life-support with CPR were assigned to the extracorporeal CPR group, and those who did not to the conventional CPR group.

Exclusion criteria that were applied to both groups were: CPR of less than $10 \mathrm{~min}$; age over 75 years; previously known severe irreversible brain damage; terminal malignancy; a traumatic origin with uncontrolled bleeding; non-cardiac arrest; and those who previously signed "Do not attempt resuscitation".?

Conventional CPR was stopped when spontaneous circulation returned and was maintained for $20 \mathrm{~min}$. The decision to discontinue unsuccessful CPR (no return of spontaneous circulation for $30 \mathrm{~min}$ ) was made after communication with the family. Exclusion criteria applying only to the extracorporeal CPR group were those who were not weaned from cardiopulmonary bypass due to post-cardiotomy shock requiring transition to extracorporeal life-support, and those who experienced shock necessitating extracorporeal life-support in an elective condition.

\section{Procedures}

Doctors in our institute were taught to regard extracorporeal life-support as an option in prolonged CPR. The decision to call the extracorporeal life-support team was made by the attending doctors in charge. Average duration from the call to team arrival was 5-7 min during the day and 15-30 min during the night shift. In general, if return of spontaneous circulation was sustained for more than 20 min after the team arrived, extracorporeal life-support would not be installed. If return of spontaneous circulation was continued for less than $20 \mathrm{~min}$, the team would wait at least $10 \mathrm{~min}$ and begin extracorporeal life-support in case of reoccurrence of arrest. 10-15 min was usually needed to set up extracorporeal life-support. Oral permission was obtained immediately, and written informed consent was later collected from the relatives. The study was approved by the institutional review board.

The equipment and management have been reported previously. The principal component of the extracorporeal CPR circuit was a heparin-bonded surface circuit including a centrifugal pump and hollow-fibre oxygenator (Medtronic, Anaheim, USA). The circuit was pre-organised without priming and was primed with saline containing $2 \mathrm{U} / \mathrm{mL}$ of heparin when the extracorporeal CPR call was initiated. We did not apply the bridge tube between the arterial and venous lines, and it was reconnected to the circuit when weaning was

\begin{tabular}{|c|c|c|}
\hline & $\begin{array}{l}\text { Extracorporeal CPR } \\
\text { group }(\mathrm{N}=59)\end{array}$ & $\begin{array}{l}\text { Conventional CPR } \\
\text { group }(\mathrm{N}=113)\end{array}$ \\
\hline Men, n (\%) & $50(84 \cdot 7)$ & $73(64 \cdot 6)$ \\
\hline \multicolumn{3}{|l|}{ Age (year) } \\
\hline Mean (SD) & $57 \cdot 4(12 \cdot 5)$ & $60 \cdot 3(13 \cdot 3)$ \\
\hline Median (range) & $61 \cdot 5(18-74)$ & $65(19-75)$ \\
\hline Age $>60$ years, $\mathrm{n}(\%)$ & $34(57 \cdot 6)$ & $67(63 \cdot 5)$ \\
\hline \multicolumn{3}{|l|}{ Pre-existing comorbidity, $\mathrm{n}(\%)$} \\
\hline Diabetes & $22(37 \cdot 3)$ & $39(34.5)$ \\
\hline Hypertension & $29(49 \cdot 2)$ & $51(45 \cdot 1)$ \\
\hline Dyslipidaemia & $10(17 \cdot 0)$ & $5(4 \cdot 4)$ \\
\hline Malignancy & $5(8 \cdot 5)$ & $15(13 \cdot 3)$ \\
\hline Lung insufficiency & $2(3 \cdot 4)$ & $12(10 \cdot 6)$ \\
\hline Stroke & $10(17 \cdot 0)$ & $8(7 \cdot 1)$ \\
\hline Chronic renal disease & $5(8 \cdot 5)$ & $21(18 \cdot 6)$ \\
\hline Cardiovascular disease & $37(62 \cdot 7)$ & $58(51 \cdot 3)$ \\
\hline Chronic hepatitis & $2(3 \cdot 4)$ & $10(8.9)$ \\
\hline \multicolumn{3}{|l|}{ Causes of arrest, n (\%) } \\
\hline Acute coronary syndrome & $37(62 \cdot 7)$ & $80(70 \cdot 8)$ \\
\hline Congestive heart failure & $6(10 \cdot 2)$ & $18(15 \cdot 9)$ \\
\hline Myocarditis & $5(8 \cdot 5)$ & $2(1 \cdot 8)$ \\
\hline Post-cardiotomy & $7(11 \cdot 9)$ & 0 \\
\hline Pulmonary embolism & $1(1 \cdot 7)$ & 0 \\
\hline Unspecified cardiac causes & $3(5 \cdot 1)$ & $13(11 \cdot 5)$ \\
\hline \multicolumn{3}{|l|}{ Department type, n (\%) } \\
\hline Internal medicine & $37(62 \cdot 7)$ & $78(69 \cdot 0)$ \\
\hline Surgery & $22(37 \cdot 3)$ & $33(29 \cdot 2)$ \\
\hline Other & & $2(1 \cdot 8)$ \\
\hline $\begin{array}{l}\text { Inotropic equivalent, } \mu \mathrm{g} / \mathrm{kg} \\
\text { per min before } \mathrm{CPR}, \mathrm{n}(\%)\end{array}$ & $55(93 \cdot 2)$ & $43(38 \cdot 1)$ \\
\hline Mean (SD) & $55 \cdot 9(65 \cdot 6)$ & $24 \cdot 7(29 \cdot 0)$ \\
\hline Median (range) & $40(2 \cdot 4-324)$ & $14 \cdot 8(1 \cdot 7-150)$ \\
\hline
\end{tabular}

See Online for webpanel 2

See Online for webfigures 1 and 2 


\begin{tabular}{|c|c|c|c|}
\hline & $\begin{array}{l}\text { Extracorporeal CPR } \\
\text { group, } \mathrm{N}(\%)\end{array}$ & $\begin{array}{l}\text { Conventional CPR } \\
\text { group, } \mathbf{N}(\%)\end{array}$ & $\begin{array}{l}\mathrm{p} \text { (extracorporeal vs } \\
\text { conventional CPR) }\end{array}$ \\
\hline $\mathrm{N}$ & 59 & 113 & \\
\hline Witnessed & $59(100)$ & $113(100)$ & \\
\hline Defibrillation* & $59(100)$ & $74(65 \cdot 5)$ & \\
\hline Left ventricle decompression & $3(5 \cdot 1)$ & 0 & \\
\hline Time period of CPR episode & & & 0.04 \\
\hline Period A (0701 h-1500 h) & $19(32 \cdot 2)$ & $34(30.0)$ & \\
\hline Period B (1501 h-2300 h) & $33(55 \cdot 9)$ & $47(41 \cdot 6)$ & \\
\hline Period C (2301 h-700 h) & $7(11 \cdot 9)$ & $32(28 \cdot 3)$ & \\
\hline CPR location & & & 0.07 \\
\hline $\begin{array}{l}\text { Intensive care unit/operating room/ } \\
\text { catheterisation laboratory }\end{array}$ & $33(55 \cdot 9)$ & $45(39 \cdot 8)$ & \\
\hline Emergency room/ward & $26(44 \cdot 1)$ & $64(56 \cdot 6)$ & \\
\hline Other &. & $4(3 \cdot 5)$ & \\
\hline First documented rhythm & & & 0.08 \\
\hline $\begin{array}{l}\text { Ventricular tachycardia/ventricular } \\
\text { fibrillation }\end{array}$ & $29(49 \cdot 2)$ & $36(31 \cdot 9)$ & \\
\hline Pulseless electrical activity & $17(28 \cdot 8)$ & $46(40 \cdot 7)$ & \\
\hline Asystole & $13(22 \cdot 0)$ & $31(27 \cdot 4)$ & \\
\hline Intubated before arrest & $39(66.1)$ & $77(68 \cdot 1)$ & 0.86 \\
\hline ROSC (ROSB) & $55(93 \cdot 2)$ & $63(55 \cdot 8)$ & $<0.0001$ \\
\hline \multicolumn{4}{|l|}{ CPR duration } \\
\hline N & 59 & 113 & \\
\hline Mean (SD), min & $52 \cdot 8(37 \cdot 2)$ & $42 \cdot 7(31 \cdot 1)$ & 0.08 \\
\hline Median (range) & $40(16-251)$ & $32(11-180)$ & \\
\hline \multicolumn{4}{|l|}{ Available maximal lactic acid level in $24 \mathrm{~h}$} \\
\hline N & 54 & 20 & \\
\hline Mean (SD) & $12 \cdot 7(6 \cdot 2)$ & $6 \cdot 2(5 \cdot 5)$ & $<0.0001$ \\
\hline Median (range) & $12 \cdot 0(2 \cdot 4-39 \cdot 7)$ & $3 \cdot 7(1 \cdot 1-20)$ & \\
\hline \multicolumn{4}{|l|}{ Subsequent intervention } \\
\hline Yes & $36(61 \cdot 0)$ & $14(12 \cdot 4)$ & $<0.0001$ \\
\hline Revascularisation & $26(44 \cdot 1)$ & $6(6 \cdot 4)$ & $<0.0001$ \\
\hline Ventricular assist device & $3(5 \cdot 1)$ & $0(0)$ & 0.04 \\
\hline Heart transplantation & $5(8 \cdot 5)$ & $0(0)$ & 0.004 \\
\hline Extracorporeal life support & & $3(3 \cdot 1)$ & \\
\hline Reperfusion for distal limb & $15(25 \cdot 4)$ &.. & $<0.0001$ \\
\hline Other & $9(15 \cdot 3) \dagger$ & $6(5 \cdot 3) \ddagger$ & 0.04 \\
\hline \multicolumn{4}{|l|}{ Hospital stay after CPR (day) } \\
\hline $\mathrm{N}$ & 55 & 44 & \\
\hline Mean & $20 \cdot 3(21 \cdot 8)$ & $25 \cdot 4(39 \cdot 5)$ & 0.44 \\
\hline Median (range) & $12(1-93)$ & $12 \cdot 0(1-174)$ & \\
\hline
\end{tabular}

ROSB=return of spontaneous heart beating (for extracorporeal CPR group). ROSC=return of spontaneous circulation (for conventional CPR group). * Defibrillation before or during CPR. †Valve replacement 3. ¥Tapping 3, pacing 2, dissecting aortic aneurysm graft 1 .

Table 2: CPR and post-CPR variables in the extracorporeal CPR group and the conventional CPR group support circuit was connected to a temperature controller within $2 \mathrm{~h}$ of beginning extracorporeal circulation to maintain normothermia. No hypothermia was applied.

Since extracorporeal CPR patients were supported by artificial circulation, we defined the return of spontaneous heart (ventricular) beating after extracorporeal CPR compared with return of spontaneous circulation in conventional CPR. Inotropic equivalent (IE), using the equation IE $(\mu \mathrm{g} / \mathrm{kg}$ per $\mathrm{min})=$ dopamine+dobutamine+ $100 \times$ epinephrine $+100 \times$ norepinephrine $+100 \times$ isoproterenol $+15 \times$ milrinone, was used to roughly estimate the severity of the pre-arrest status. ${ }^{13}$ Daily echocardiography was essential to estimate myocardial recoverability and to detect possible thrombus formation within the left ventricle.

Weaning, defined as successful separation from extracorporeal life-support without mortality in $12 \mathrm{~h}$, was not attempted until $72 \mathrm{~h}$ after initiation. Ventricular assist device and heart transplantation were alternatives in the absence of contraindications when weaning was unsuccessful in 5-7 days. Cessation of extracorporeal life-support was considered if severe neurological impairment persisted for more than 7 days without signs of recovery.

Consciousness status was assessed every $12 \mathrm{~h}$. The functional status of survivors ( 1 and $2=$ good neurological outcome vs 3 and 4=poor) after discharge from hospital was analysed according to the Glasgow-Pittsburgh cerebral-performance categories (CPC) score. $^{18}$ The patient was regarded as discharged on the day of death (CPC 5), or at the end of the hospital course when they went home with good neurological outcome (CPC 1 or 2) or to a nursing home with poor neurological outcome (CPC 3 or 4).

The primary endpoint was survival to hospital discharge. The difference in survival curves, assessed at 30 days and 1 year, was used as the secondary endpoint. Other parameters, such as the proportion of return of spontaneous heart beat or return of spontaneous circulation, the cumulative survival rate at $24 \mathrm{~h}, 3$ days, 14 days, 30 days, 6 months, and 1 year, were summarised.

\section{Propensity score methods}

Propensity score matching is a method used to balance observed covariates in the two treatment groups. ${ }^{19-21}$ In this study, the propensity score was the conditional probability for getting extracorporeal CPR, as a binary dependent variable, under a set of measurements. Age, sex, initial cardiac rhythm, time point of CPR, CPR duration, the presence of comorbidities were added into a non-parsimonious multivariable logistic regression model to predict the effect of extracorporeal life-support. The predicted probability derived from the logistic equation was used as the propensity score for each individual.

Extracorporeal and conventional CPR patients were pooled and sorted according to their propensity score 
in ascending order. The selection process began from the first two cases with the lowest propensity score. If one underwent extracorporeal $\mathrm{CPR}$ and the other underwent conventional CPR, both were selected as a matched pair. If this was not the case, then four cases were included. If there were two extracorporeal CPR and two conventional CPR cases, the four were selected as two matched pairs. In the same way, extracorporeal CPR and conventional CPR cases were matched by their propensity score in 1:1, 2:2, 3:3, or $4: 4$ blocks. A patient who did not have a suitable match within the acceptable rank range was excluded from further analysis, and the matching process moved down the sort list until all possible matched pairs were included. The selected patients formed well-matched 1:1 pairs in both groups (extracorporeal CPR-M and conventional CPR-M).

\section{Statistical analysis}

Categorical variables were compared with $\chi^{2}$ test (or Fisher's exact test) and continuous variables with Student's $t$ test. The survival time to discharge was defined as the duration from the day of CPR to the day of discharge, either dead or alive. A case that survived to discharge was regarded as censored (non-event) on the day of discharge. Log-rank test was used to compare the survival difference between the extracorporeal and conventional CPR groups. In the observational cohort, extracorporeal CPR status and covariates (age, sex, initial rhythm, CPR duration, CPR timing, and CPR location) were added into a Cox regression model to estimate the hazards.

Kaplan-Meier curves, with follow-up of up to 30 days and 1 year, were plotted to show survival trend. Log-rank test and Cox regression model were used to compare the hazard between the two matched groups. Hazard ratio, 95\% CI, and p value were reported. The survival time was defined as the duration from CPR to death in the mortality cases, and in the survivors as the duration from CPR to censorship-ie, discharge, 30 days, and 1 year. A p value of less than 0.05 was regarded as significant.

A logistic regression model was used for the propensity match using SPSS version 13.0 (SPSS, Chicago, USA). Odds ratio (OR) and $\mathrm{p}$ values were used to represent the probability that a patient would receive extracorporeal life-support. Propensity scores in both extracorporeal and conventional CPR groups were used to draw box-plots. If two-thirds of conventional CPR patients died and extracorporeal CPR resulted in a $50 \%$ risk reduction, we estimated that 35 patients in either group would be needed to achieve $80 \%$ statistical power (given $\alpha=0 \cdot 05$ ). After the 1:1 matched groups were assembled, the primary and secondary endpoints were compared accordingly.

This trial is registered with ClinicalTrials.gov, NCT00173615.

\begin{tabular}{|c|c|c|}
\hline & Extracorporeal CPR group & Conventional CPR group \\
\hline $\mathrm{N}$ & 59 & 113 \\
\hline \multicolumn{3}{|c|}{ Duration of extracorporeal membrane oxygenation $(\mathrm{h})$} \\
\hline Mean (SD) & $110(128)$ &.. \\
\hline Median (range) & $69(2-771)$ &.. \\
\hline $\begin{array}{l}\text { Weaned off extracorporeal } \\
\text { membrane oxygenation, } \mathrm{n}(\%)\end{array}$ & $29(49 \cdot 2)$ &.. \\
\hline \multicolumn{3}{|l|}{ CPC status at discharge } \\
\hline 1 or $2^{*}, \mathrm{n}(\%)$ & $14(23 \cdot 7)$ & $12(10 \cdot 6)$ \\
\hline Odds ratio ( $95 \% \mathrm{Cl}, \mathrm{p}$ value) & $2 \cdot 6\left(95 \% \mathrm{Cl} 1 \cdot 1-6 \cdot 7, \mathrm{p}=0.02^{*}\right)$ & $2.6\left(95 \% \mathrm{Cl} 1.1-6 \cdot 7, \mathrm{p}=0.02^{*}\right)$ \\
\hline \multicolumn{3}{|l|}{ CPC status at 1 year } \\
\hline 1 or $2, \mathrm{n}(\%)$ & $9(15 \cdot 3)$ & $10(8 \cdot 9)$ \\
\hline Odds ratio ( $95 \% \mathrm{Cl}, \mathrm{p}$ value) & $1 \cdot 9(95 \% \mathrm{Cl} 0 \cdot 6-5 \cdot 4, \mathrm{p}=0 \cdot 20)$ & $1.9(95 \% \mathrm{Cl} 0.6-5 \cdot 4, \mathrm{p}=0.20)$ \\
\hline
\end{tabular}

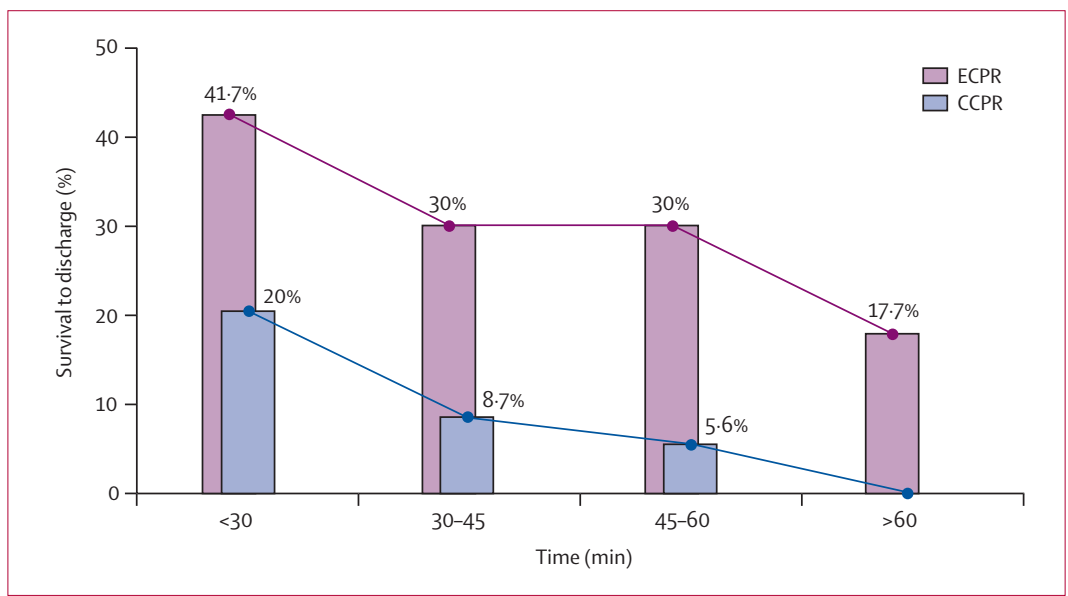

Figure 1: Relation between CPR duration and the survival rate to discharge

$E C P R=$ extracorporeal $C P R$. CCPR=conventional CPR.

\begin{tabular}{|llll|}
\hline & Hazard ratio & $95 \% \mathrm{Cl}$ & $\mathrm{p}$ \\
\hline $\begin{array}{l}\text { Ventricular tachycardia/ } \\
\text { ventricular fibrillation }\end{array}$ & 0.58 & $0.40-0.83$ & 0.003 \\
$\begin{array}{l}\text { Use of extracorporeal } \\
\text { membrane oxygenation }\end{array}$ & 0.50 & $0.33-0.74$ & 0.001 \\
$\begin{array}{l}\text { CPR duration (+1 min) } \\
\text { Age (+1 year) }\end{array}$ & 1.007 & $1.003-1.011$ & 0.002 \\
$\begin{array}{l}\text { Men } \\
\text { Period C (midnight) }\end{array}$ & 1.01 & $0.99-1.02$ & 0.07 \\
$\begin{array}{l}\text { Intensive scenario } \\
\text { Intensive scenario=intensive care unit, operating room, or catheterisation room. }\end{array}$ & 1.04 & $0.72-1.5$ & 0.83 \\
\hline $\begin{array}{l}\text { Table 4: Multivariate Cox regression analysis for the factors associated } \\
\text { with the survival to hospital discharge }\end{array}$ & $0.71-1.5$ & 0.82 \\
\hline
\end{tabular}

\section{Role of the funding source}

The funding source had no role in study design, data collection, data analysis, data interpretation, or writing of the report. The corresponding author had full access to all the data in the study and had final responsibility for the decision to submit for publication. 


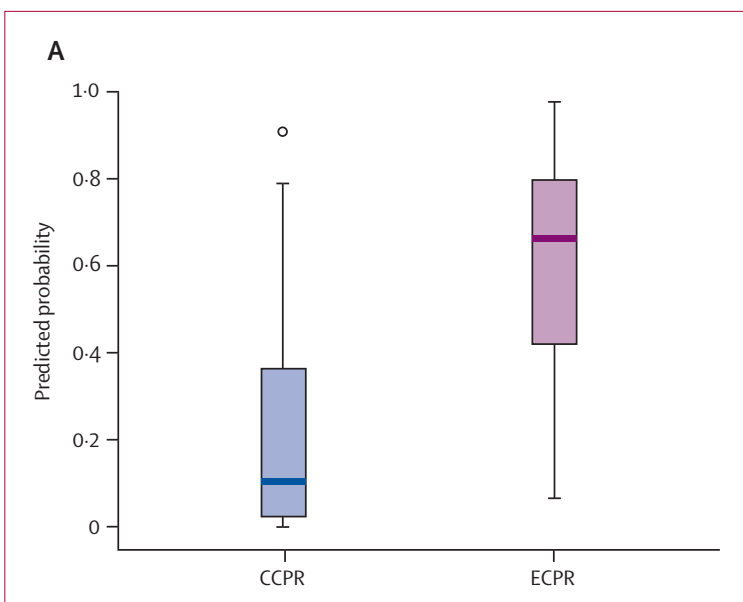

B

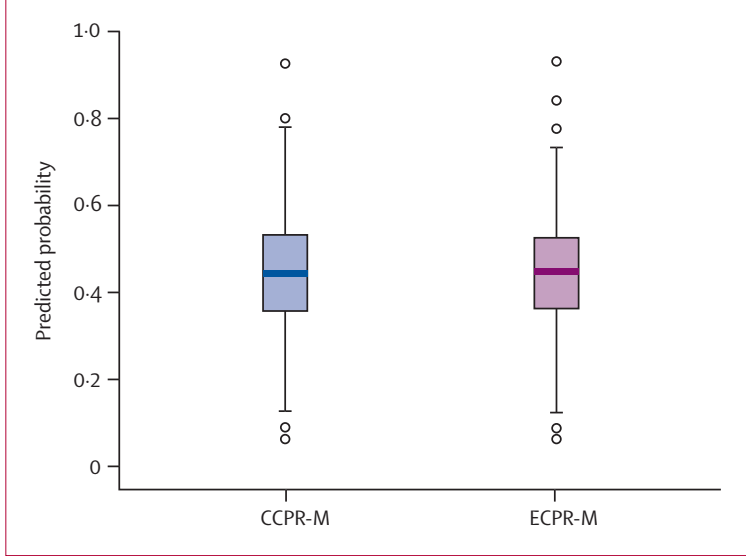

Figure 2: Propensity analysis

Distribution of propensity scores in (A) the conventional CPR and extracorporeal CPR groups, and (B) the matched conventional CPR (CCPR-M) and extracorporeal CPR (ECPR-M) groups.

\section{Results}

Of the 975 patients with in-hospital cardiac arrest events recorded during the 36-month observational study, 113 received conventional $\mathrm{CPR}$ and 59 received extracorporeal CPR, according to the selection criteria (webfigures 1 and 2). The baseline characteristics of both groups are shown in table 1 , and CPR and post-CPR variables are shown in table 2 . CPR duration did not significantly differ between the two groups $(p=0 \cdot 08)$. CPR call occurred less frequently in period $\mathrm{C}$ $(2301 \mathrm{~h}-0700 \mathrm{~h})$ in the extracorporeal group $(\mathrm{p}=0 \cdot 04)$. The first documented rhythm of ventricular tachycardia or ventricular fibrillation was higher in the extracorporeal CPR group than in the conventional CPR group, but the distribution of ventricular tachycardia or ventricular fibrillation, pulseless electrical activity, and asystole were not significant $(\mathrm{p}=0 \cdot 08)$. Return of spontaneous beating in the extracorporeal group was higher than return of spontaneous circulation in the conventional group, despite a longer CPR duration (table 2).
More subsequent interventions were done in the extracorporeal group than in the conventional group. These interventions included revascularisation, implantation of a ventricular assist device, and heart transplantation (table 2). Three patients in the conventional group required extracorporeal life-support because of persistent shock after return of spontaneous circulation, the interval between extracorporeal lifesupport and return of spontaneous circulation being 24 (SD 12) h. They were analysed in the conventional group (intention to treat). The length of hospital stay after CPR was similar between groups.

At discharge, the extracorporeal group had a roughly $20 \%$ increase in survival rate and better neurological outcome compared with the conventional group (table 3). The adverse relation between CPR duration and the survival rate to discharge is shown in figure 1.

17 patients in the extracorporeal group (28.8\%) and 14 patients $(12 \cdot 3 \%)$ in the conventional group survived to discharge. The cumulative survival rate in the extracorporeal group was $93 \cdot 2 \%$ (at $24 \mathrm{~h}$ ), $76 \cdot 3 \%$ (3 days), $44 \cdot 1 \%$ (14 days), 33.9\% (30 days), $28 \cdot 8 \%$ (6 months), and $18.6 \%$ (1 year; 11 survivors). In the conventional group, the cumulative survival was $38.1 \%$ (at $24 \mathrm{~h}$ ), $31.0 \%$ (3 days), 21.2\% (14 days), 15.0\% (30 days), 11.5\% (6 months), and $9.7 \%$ (1 year; 11 survivors). Kaplan-Meier analysis showed a survival benefit favouring the extracorporeal group over the conventional group at discharge (log-rank $\mathrm{p}<0.0001$ ), and also at 30 days $(\mathrm{p}=0 \cdot 003)$ and 1 year $(\mathrm{p}=0 \cdot 007)$. Multivariate Cox regression model analysis indicated that extracorporeal life-support use and first documented rhythm of ventricular tachycardia or ventricular fibrillation were positively associated with the survival to discharge, and CPR duration was negatively associated (table 4). When the interaction between return of spontaneous beating in the extracorporeal group and return of spontaneous circulation in the conventional group was added to the model, the new variable was not associated with the survival $(p=0 \cdot 50)$. This finding suggested a lack of survival benefit in the return of spontaneous beating responders over the return of spontaneous circulation responders.

There were six late deaths in the extracorporeal group between 6 and 12 months; the causes were underlying malignancy (two), progressive heart failure (two), and another sepsis episode (two). In the conventional group, three late deaths occurred in 12 months, one related to a persistent cardiac event and two to pneumonia.

In the propensity score assignment, extracorporeal lifesupport was found to be positively associated with an increase in CPR time (OR 1.01 per min, $p=0 \cdot 05$ ), initial presentation with ventricular tachycardia or ventricular fibrillation (OR 2.5, p=0.04 compared with pulseless electrical activity and OR $2 \cdot 4, \mathrm{p}=0.07$ compared with asystole), the presence of dyslipidaemia (OR 4.9, $\mathrm{p}=0 \cdot 02$ ), previous cardiovascular or cerebrovascular events (OR $3 \cdot 5, \quad p=0 \cdot 03$ ), and negatively associated with 
increased age (OR 0.98 per year, $\mathrm{p}=0.03)$ and the presence of end-stage renal disease (OR $0 \cdot 18, p=0 \cdot 009)$. Mean propensity score was $0 \cdot 60$ (SD 0.24) in the extracorporeal group and $0.20(0.23)$ in the conventional group $(\mathrm{p}<0 \cdot 0001$; figure 2A).

The propensity score-matching process selected 46 patients from the extracorporeal CPR-M group and the other 46 from the conventional CPR-M group for further analysis. No case in conventional CPR-M received extracorporeal life-support later in the course. Propensity score was 0.43 (SD $0 \cdot 18$ ) in the extracorporeal CPR-M group and $0.44(0.18)$ in the conventional CPR-M group ( $\mathrm{p}=0.94$; figure $2 \mathrm{~B})$. Baseline characteristics, including initial cardiac rhythm, CPR duration, and subsequent percutaneous coronary intervention, were similar in the two groups (table 5).

The return of spontaneous beating rate in the extracorporeal CPR-M group was statistically higher than the return of spontaneous circulation rate in the conventional CPR-M group ( $\mathrm{p}<0 \cdot 0001) .15$ cases in the extracorporeal CPR-M group (32.6\%) and eight cases in the conventional CPR-M group survived to discharge (17.4\%). Kaplan-Meier analysis showed a survival benefit favouring extracorporeal CPR-M over conventional CPR-M at discharge (HR 0.51, 95\% CI $0 \cdot 35-0 \cdot 74, \mathrm{p}<0 \cdot 0001)$. Neurological outcome (categorised into CPC $1 / 2$, CPC $3 / 4$, and death) showed no difference at discharge $(\mathrm{p}=0 \cdot 09$, table 5$)$.

The cumulative survival rate was $65 \cdot 2 \%$ (at $24 \mathrm{~h}$ ), $52 \cdot 2 \%$ (3 days), 37.0\% (14 days), 34.8\% (30 days), 32.6\% (6 months), and $19.6 \%$ (1 year; nine survivors) in the extracorporeal CPR-M group and $41.3 \%(24 \mathrm{~h}), 34.8 \%$ (3 days), 23.9\% (14 days), 17.4\% (30 days), 15.2\% (6 months), and $13.0 \%$ (1 year; six survivors) in the conventional CPR-M group. Survival analysis with the Kaplan-Meier plot showed a better survival in the extracorporeal CPR-M group at the end of 30 days $(\log$-rank $\mathrm{p}=0 \cdot 042)$ and at 1 year $(\log$-rank $\mathrm{p}=0 \cdot 003$; figure 3). The hazard ratio of extracorporeal CPR over conventional CPR was 0.47 (95\% CI 0.28-0 77, $\mathrm{p}=0 \cdot 003$ ) if the survival curves were trimmed at 30 days. Extracorporeal CPR still showed a survival benefit at the end of 1 year (HR 0.53 , 95\% CI $0.33-0.83, p=0 \cdot 006$ ). Neurological outcome showed no difference at 1 year $(\mathrm{p}=0 \cdot 27$, table 5$)$.

\section{Discussion}

Our observational study focusing on adult in-hospital cardiac arrest of cardiac origin in a single institute has shown a survival benefit in patients receiving extracorporeal CPR compared with those receiving conventional CPR. Although randomisation is, in theory, the proper way to take account of unknown confounders, propensity analysis has still shown a short-term and long-term survival benefit favouring extracorporeal CPR when known confounding factors were matched.
Extracorporeal circulation had previously been applied in several critical conditions, including acute respiratory distress syndrome, cardiogenic or postcardiotomy shock, and bridge to ventricular assist device, transplantation,

\begin{tabular}{|c|c|c|c|}
\hline & $\begin{array}{l}\text { Extracorporeal CPR-M } \\
(\mathrm{N}=46)\end{array}$ & $\begin{array}{l}\text { Conventional CPR-M } \\
(\mathrm{N}=46)\end{array}$ & $\mathrm{p}$ \\
\hline \multicolumn{4}{|l|}{ Baseline characteristics } \\
\hline Age (mean [SD]) & $57(14)$ & $55(15)$ & 0.64 \\
\hline CPR duration (min) & $53(41)$ & $47(33)$ & 0.44 \\
\hline Men, n (\%) & $39(85)$ & $40(87)$ & 0.76 \\
\hline Initial rhythm, n (\%) & & & 0.81 \\
\hline $\begin{array}{l}\text { Ventricular tachycardia/ventricular } \\
\text { fibrillation }\end{array}$ & $21(45 \cdot 7)$ & $19(41 \cdot 3)$ & \\
\hline Pulseless electrical activity & $15(32 \cdot 6)$ & $18(39 \cdot 1)$ & \\
\hline Asystole & $10(21 \cdot 7)$ & $9(19 \cdot 6)$ & \\
\hline \multicolumn{4}{|l|}{ Causes of arrest ${ }^{*}, \mathrm{n}(\%)$} \\
\hline Acute coronary syndrome & $28(60 \cdot 8)$ & $33(71 \cdot 7)$ & \\
\hline Congestive heart failure & $5(10 \cdot 9)$ & $9(19 \cdot 6)$ & \\
\hline Myocarditis & $5(10 \cdot 9)$ & $1(2 \cdot 2)$ & \\
\hline Post-cardiotomy & $4(8 \cdot 7)$ & 0 & \\
\hline Pulmonary embolism & $1(2 \cdot 2)$ & 0 & \\
\hline Unspecified cardiac causes & $3(6 \cdot 5)$ & $3(6 \cdot 5)$ & \\
\hline Diabetes & $15(32 \cdot 6)$ & $15(32 \cdot 6)$ & 1.00 \\
\hline Hypertension & $17(37 \cdot 0)$ & $22(47 \cdot 8)$ & 0.29 \\
\hline Dyslipidaemia & $5(10 \cdot 9)$ & $4(8 \cdot 7)$ & 0.73 \\
\hline Malignancy & $4(8.7)$ & $3(6 \cdot 5)$ & 0.69 \\
\hline Chronic obstructive pulmonary disease & $2(4 \cdot 3)$ & $2(4 \cdot 3)$ & 1.00 \\
\hline Cerebrovascular accidents & $6(13 \cdot 0)$ & $5(10 \cdot 9)$ & $0 \cdot 75$ \\
\hline Abnormal liver function & $2(4 \cdot 3)$ & $3(6 \cdot 5)$ & 0.65 \\
\hline Haemodialysis & $5(10 \cdot 9)$ & $4(8 \cdot 7)$ & 0.73 \\
\hline Documented heart disease & $24(52 \cdot 2)$ & $30(65 \cdot 2)$ & 0.39 \\
\hline $\begin{array}{l}\text { Location (intensive care unit/operating } \\
\text { room/catheterisation room) }\end{array}$ & $25(54 \cdot 4)$ & $24(52 \cdot 2)$ & 0.83 \\
\hline Period C (midnight) & $7(15 \cdot 2)$ & $10(21 \cdot 8)$ & 0.65 \\
\hline Department & & & 0.56 \\
\hline Medicine & $30(65 \cdot 2)$ & $31(67 \cdot 4)$ & \\
\hline Surgery & $16(34 \cdot 8)$ & $14(30 \cdot 4)$ & \\
\hline Other & 0 & $1(2 \cdot 2)$ & \\
\hline $\begin{array}{l}\text { Subsequent percutaneous coronary } \\
\text { intervention }\end{array}$ & $8(17 \cdot 4)$ & $3(6 \cdot 5)$ & $0 \cdot 11$ \\
\hline \multicolumn{4}{|l|}{ Clinical endpoints } \\
\hline ROSB/ROSC,$+ \mathrm{n}(\%)$ & $42(91 \cdot 3)$ & $24(52 \cdot 2)$ & $<0.001 \ddagger$ \\
\hline \multicolumn{4}{|l|}{ Neurological outcome } \\
\hline CPC status at discharge & $\mathrm{n}(\%)$ & $n(\%)$ & \\
\hline 1 or 2 & $14(30 \cdot 4)$ & $7(15 \cdot 2)$ & 0.09 \\
\hline 3 or 4 & $1(2 \cdot 2)$ & $1(2 \cdot 2)$ & 0.09 \\
\hline 5 (death) & $31(67 \cdot 4)$ & $38(82 \cdot 6)$ & 0.09 \\
\hline CPC status at 1 year & $\mathrm{n}(\%)$ & n (\%) & \\
\hline 1 or 2 & $9(19 \cdot 5)$ & $5(10 \cdot 8)$ & 0.27 \\
\hline 3 or 4 & $1(2 \cdot 2)$ & $1(2 \cdot 2)$ & 0.27 \\
\hline 5 (death) & $36(78 \cdot 3)$ & $40(87 \cdot 0)$ & 0.27 \\
\hline $\begin{array}{l}\text { ROSC=return of spontaneous circulation for } \\
\text { extracorporeal CPR-M. }{ }^{*} p=0 \cdot 10 \text {. }+ \text { Odds ratio }\end{array}$ & $\begin{array}{l}\text { tional CPR-M. ROSB=retu } \\
\%(13 \cdot 0-31 \cdot 2) . \neq p<0.05 .\end{array}$ & f spontaneous beatin & \\
\hline
\end{tabular}




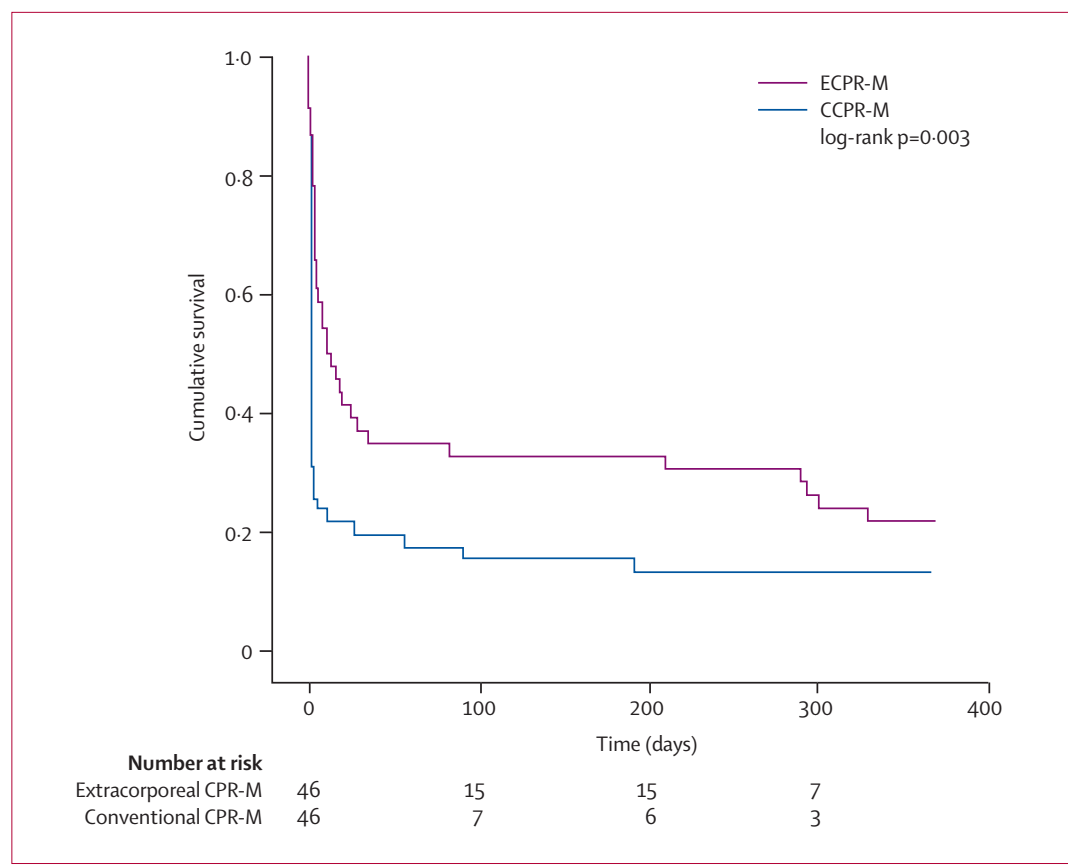

Figure 3: Kaplan-Meier plot of the survival curves in the extracorporeal CPR-M and conventional CPR-M groups for 1 year extracorporeal CPR responders and conventional CPR responders, but the preliminary result did not show a survival difference. Since only a small proportion of the original registry was included in the subgroup analysis, further examination into the most suitable application of extracorporeal life-support in patients with return of spontaneous circulation after conventional CPR is warranted.

The quality of CPR might not have been well controlled between the two groups. ${ }^{29,30}$ Although the propensity-score approach could reduce selection bias and confounding factors inherent in the observational study, a key limitation is that bias could remain if there are unmeasured or unknown confounders that are not incorporated into the propensity score.

The difference in subsequent interventions in the conventional and extracorporeal groups could be attributed to some extent to observer bias (which might have occurred even in a randomised study if it is not blinded). We tried to reduce observer bias by locating (or relocating) the patients in both groups to the intensive care unit. A subsequent decision was made according to their clinical condition, not simply to their life-support status. Conversely, fewer patients in the conventional CPR group could survive to definite therapy. The greater number of subsequent investigations in the extracorporeal CPR group was also attributed to the differential effect of intervention. In the propensity analysis, later percutaneous coronary intervention was similar in the extracorporeal CPR-M group and conventional CPR-M group (table 5).

Previous studies have suggested that applying mild hypothermia $\left(34^{\circ} \mathrm{C}\right)$ for 24 or $48 \mathrm{~h}$ in patients receiving extracorporeal life-support was both feasible and safe. Since our observational cohort was started in 2003, the institutional review board did not approve the use of hypothermia at its experimental stage. However, therapeutic hypothermia is currently recommended in cardiac arrest of cardiac origin. Further research should stress the additive or synergistic effect of hypothermia in extracorporeal CPR for adult cardiac patients.

Extracorporeal CPR might be recommended for adult in-hospital cardiac arrest patients of cardiac origin who have undergone CPR for more than $10 \mathrm{~min}$ and could provide a short-term and long-term survival advantage. Although the observed survival benefit of extracorporeal CPR over conventional CPR is in part attributed to selection bias, the use of propensity analysis that equalised potential prognostic predictors has shown a beneficial effect in short-term and long-term survival with extracorporeal life-support. There was no significant difference in survival between return of spontaneous beating from extracorporeal CPR and return of spontaneous circulation from conventional CPR. Further studies will be needed to identify potential subgroups in in-hospital cardiac arrest patients who could benefit from extracorporeal CPR. 
Conflict of interest statement

Y-S Chen was supported by grants from the National Taiwan University Hospital and National Science Council, Taiwan (NTUH97-097-000857, NSC 93-2314-B-002-235, 94-2314-B-002-121, 95-2745-B-002-232, 96-2314-B-002-166, and 96-2314-B-002-039) for the study. The other authors declare that they have no conflict of interest.

\section{Acknowledgments}

The study was supported by grants from the National Science Council, Taiwan: NSC 93-2314-B-002-235, 94-2314-B-002-121, 95-2745-B-002-232, and 96-2314-B-002-166.

\section{References}

1 Eisenberg MS, Mengert TJ. Cardiac resuscitation. N Engl J Med 2001; 344: 1304-13.

2 Cooper S, Janghorbani M, Cooper G. A decade of in-hospital resuscitation: outcomes and prediction of survival? Resuscitation 2006; 68: 231-37.

3 Peberdy MA, Kaye W, Ornato JP, et al. Cardiopulmonary resuscitation of adults in the hospital: a report of 14720 cardiac arrests from the National Registry of Cardiopulmonary Resuscitation. Resuscitation 2003; 58: 297-308.

4 Hajbaghery MA, Mousavi G, Akbari H. Factors influencing survival after in-hospital cardiopulmonary resuscitation. Resuscitation 2005; 66: 317-21.

5 Shih CL, Lu TC, Jerng JS, et al. A web-based Utstein style registry system of in-hospital cardiopulmonary resuscitation in Taiwan. Resuscitation 2007; 72: 394-403.

6 Kennedy JH. The role of assisted circulation in cardiac resuscitation. JAMA 1966; 197: 615-18.

7 Chen YS, Chao A, Yu HY, et al. Analysis and results of prolonged resuscitation in cardiac arrest patients rescued by extracorporeal membrane oxygenation. J Am Coll Cardiol 2003; 41: 197-203.

8 Nagao K, Hayashi N, Kanmatsuse K, et al. Cardiopulmonary cerebral resuscitation using emergency cardiopulmonary bypass, coronary reperfusion therapy and mild hypothermia in patients with cardiac arrest outside the hospital. J Am Coll Cardiol 2000; 36: 776-83.

9 Schwarz B, Mair P, Margreiter J, et al. Experience with percutaneous venoarterial cardiopulmonary bypass for emergency circulatory support. Crit Care Med 2003; 31: 758-64.

10 Morris MC, Wernovsky G, Nadkarni VM. Survival outcomes after extracorporeal cardiopulmonary resuscitation instituted during active chest compressions following refractory in-hospital pediatric cardiac arrest. Pediatr Crit Care Med 2004; 5: 440-46.

11 Alsoufi B, Al-Radi OO, Nazer RI, et al. Survival outcomes after rescue extracorporeal cardiopulmonary resuscitation in pediatric patients with refractory cardiac arrest. J Thorac Cardiovasc Surg 2007; 134: 952-59.

12 Thiagarajan RR, Laussen PC, Rycus PT, Bartlett RH, Bratton SL. Extracorporeal membrane oxygenation to aid cardiopulmonary resuscitation in infants and children. Circulation 2007; 116: 1693-700.

13 Chen YS, Ko WJ, Chi NH, et al. Risk factor screening scale to optimize treatment for potential heart transplant candidates under extracorporeal membrane oxygenation. Am J Transplant 2004; 4: $1818-25$.

14 Chen JS, Ko WJ, Yu HY, et al. Analysis of the outcome for patients experiencing myocardial infarction and cardiopulmonary resuscitation refractory to conventional therapies necessitating extracorporeal life support rescue. Crit Care Med 2006; 34: 950-57.
15 Chen YS, Yu HY, Huang SC, et al. Experience and result of extracorporeal membrane oxygenation in treating fulminant myocarditis with shock: what mechanical support should be considered first? J Heart Lung Transplant 2005; 24: 81-87.

162005 American Heart Association Guidelines for Cardiopulmonary Resuscitation and Emergency Cardiovascular Care. Circulation 2005; 112 (24 suppl): IV1-203.

17 Huang SC, Yu HY, Ko WJ, Chen YS. Pressure criterion for placement of distal perfusion catheter to prevent limb ischemia during adult extracorporeal life support. J Thorac Cardiovasc Surg 2004; 128: 776-77.

18 Prohl J, Rother J, Kluge S, et al. Prediction of short-term and long-term outcomes after cardiac arrest: a prospective multivariate approach combining biochemical, clinical, electrophysiological, and neuropsychological investigations. Crit Care Med 2007; 35: 1230-37.

19 Haviland A, Nagin DS, Rosenbaum PR. Combining propensity score matching and group-based trajectory analysis in an observational study. Psychol Methods 2007; 12: 247-67.

20 Feinstein A. The role of observational studies in the evaluation of therapy. Stat Med 1984; 3: 341-45.

21 Ahmed A, Zannad F, Love TE, et al. A propensity-matched study of the association of low serum potassium levels and mortality in chronic heart failure. Eur Heart J 2007; 28: 1334-43.

22 Smedira NG, Moazami N, Golding CM, et al. Clinical experience with 202 adults receiving extracorporeal membrane oxygenation for cardiac failure: survival at five years. J Thorac Cardiovasc Surg 2001; 122: 92-102.

23 Ko WJ, Lin CY, Chen RJ, Wang SS, Lin FY, Chen YS. Extracorporeal membrane oxygenation support for adult postcardiotomy cardiogenic shock. Ann Thorac Surg 2002; 73: 538-45.

24 Chen YS, Ko WJ, Lin FY, et al. Preliminary result of an algorithm to select proper ventricular assist devices for high-risk patients with extracorporeal membrane oxygenation support. J Heart Lung Transplant 2001; 20: 850-57.

25 Tayara W, Starling RC, Yamani MH, Wazni O, Jubran F, Smedira N Improved survival after acute myocardial infarction complicated by cardiogenic shock with circulatory support and transplantation: comparing aggressive intervention with conservative treatment. J Heart Lung Transplant 2006; 25: 504-09.

26 Massetti M, Tasle M, Le Page O, et al. Back from irreversibility: extracorporeal life support for prolonged cardiac arrest. Ann Thorac Surg 2005; 79: 178-83.

27 Sung K, Lee YT, Park PW, et al. Improved survival after cardiac arrest using emergent autopriming percutaneous cardiopulmonary support. Ann Thorac Surg 2006; 82: 651-56.

28 Takasu A, Sakamoto T, Okada Y. Arterial base excess after CPR: the relationship to CPR duration and the characteristics related to outcome. Resuscitation 2007; 73: 394-99.

29 Kramer-Johansen J, Edelson DP, Losert H, Kohler K, Abella BS. Uniform reporting of measured quality of cardiopulmonary resuscitation (CPR). Resuscitation 2007; 74: 406-17.

30 Abella BS, Edelson DP, Kim S, et al. CPR quality improvement during in-hospital cardiac arrest using a real-time audiovisual feedback system. Resuscitation 2007; 73: 54-61. 